November 2021

\title{
An Exploration of Concussion Assessment and Management Knowledge in Athletic Therapy Students
}

Colin D. King

Acadia University, colin.king@acadiau.ca

Loriann M. Hynes

York University, Ihynes@yorku.ca

Follow this and additional works at: https://digitalcommons.georgiasouthern.edu/ij-sotl

\section{Recommended Citation}

King, Colin D. and Hynes, Loriann M. (2021) "An Exploration of Concussion Assessment and Management Knowledge in Athletic Therapy Students," International Journal for the Scholarship of Teaching and Learning: Vol. 15: No. 2, Article 11.

Available at: https://doi.org/10.20429/ijsotl.2021.150211 


\title{
An Exploration of Concussion Assessment and Management Knowledge in Athletic Therapy Students
}

\begin{abstract}
Recent research has found substantial gaps in knowledge surrounding concussion assessment and management in various groups of Canadian healthcare professionals, including medical students, physiotherapists, chiropractic students, and family medicine physicians. The purpose of this project was to explore concussion knowledge in a sample of athletic therapy students and to use these findings to make practical pedagogical recommendations to improve concussion education. A sequential explanatory mixed-methods approach (initial questionnaire, student interviews, clinical educator interviews) was used to investigate the research question. The findings showed a large gap between theoretical knowledge and practical abilities to assess and manage concussions. Additionally, students felt less prepared to assist throughout the entire continuum of concussion care (from initial recognition to return-to-play). Based on these findings, educators should consider innovative pedagogical strategies that focus on true competence development in concussion assessment and management while bridging the gap between foundational theory and practical application/skill development.
\end{abstract}

\section{Keywords}

concussion education, competence development, athletic therapy pedagogy, health professional education

\section{Creative Commons License}

cc) (i) $(9$

This work is licensed under a Creative Commons Attribution-Noncommercial-No Derivative Works 4.0 License. 
IJ-SoTL, Vol. 15 [2021], No. 2, Art. 11

\title{
An Exploration of Concussion Assessment and Management Knowledge in Athletic Therapy Students
}

\author{
Colin D. King' and Loriann M. Hynes² \\ I.Acadia University \\ 2.York University
}

Received: 23 June 2020;Accepted: 7 July 2021

\begin{abstract}
Recent research has found substantial gaps in knowledge surrounding concussion assessment and management in various groups of Canadian healthcare professionals, including medical students, physiotherapists, chiropractic students, and family medicine physicians. The purpose of this project was to explore concussion knowledge in a sample of athletic therapy students and to use these findings to make practical pedagogical recommendations to improve concussion education. A sequential explanatory mixed-methods approach (initial questionnaire, student interviews, clinical educator interviews) was used to investigate the research question. The findings showed a large gap between theoretical knowledge and practical abilities to assess and manage concussions. Additionally, students felt less prepared to assist throughout the entire continuum of concussion care (from initial recognition to return-to-play). Based on these findings, educators should consider innovative pedagogical strategies that focus on true competence development in concussion assessment and management while bridging the gap between foundational theory and practical application/skill development.
\end{abstract}

\section{INTRODUCTION}

In Canada, concussion injuries in youth and adolescents have increased four-fold over the period of 2003-20I3 with the most common mechanism of concussion occurring during sport participation (Zemek et al., 2017). Those who have incurred a concussion injury often present to a wide variety of primary care and specialist physicians (Burke et al., 20I2), however currently, there is a significant lack of knowledge of, and consistency in, how health care practitioners of all types both assess and manage patients with concussive injuries (Carson et al., 2016; Lebrun et al., 20I3; Stoller et al., 20I4; Zemek et al., 20l4). The lack of consistent concussion curriculum for physicians in medical school is concerning (Burke et al., 20I2), in particular due to the current recommendation to seek medical attention from a doctor when a concussion is suspected (Parachute 2020a). Concussion management is challenging for patients and healthcare professionals alike, as the signs, symptoms, and recovery rates vary across the populations and no single test or diagnostic tool currently exists to confirm a diagnosis. Of significant alarm in the report by Zemek et al. (2017) is that concussion-related visits to the emergency departments and doctor offices have demonstrated a steep increase from 2010 onwards. This is further complicated by the fact that emergency department physicians are significantly less aware of any versions of the Concussion in Sport Group's (CISG's) Consensus Statements (Carson et al., 20I6), and the low percentage of correct physician-directed application of Returnto-Learn (RTL) and Return-to-Play (RTP) recommendations for patients (Zemek et al., 20I4).

The current lack of concussion knowledge, diagnosis, and proper management is a challenge across other health care professions as well. Chiropractors were identified to possess similar concussion skills and knowledge as medical doctors but acknowledged that significant gaps pertaining to the injury still existed and that upon graduation, these professionals may not have enough knowledge to engage in optimal concussion management (Kazemi et al., 2016). In another study, a large sample of physical therapists were found to have a solid foundation of concussion knowledge and confidence in their assessment and management skills (Yorke et al., 2016). However, those in the sample demonstrated a lack of confidence in RTP decisions and further gaps were identified in the utilization of concussion severity scales, youth concussion management and the use of neuroimaging for concussion diagnosis (Yorke et al., 2016).

Athletic Therapists and Athletic Trainers have long served on the sidelines of sport, recognized as typically the first providers to identify and evaluate athletes with suspected concussions, and are an integral part of the post-injury management and RTP decision-making process (Broglio et al., 20l4). Their presence is repeatedly recommended in higher risk sports where there is a greater potential for concussions to occur between participants, in an effort to identify when a suspected concussion has occurred and how to immediately manage it (Broglio et al., 2014; Creating Rowan's Law, 2017). Despite this accepted position and knowledge of the Athletic Therapist's/Trainer's skillset, there is limited literature that has evaluated concussion knowledge amongst athletic therapy and training professionals, both in Canada and the United States.

The Commission on Accreditation of Athletic Training Education (CAATE) in the United States recently established the 2020 Standards for Accreditation of Professional Athletic Training Programs (CAATE, 20I8). The standards relating to concussion, identify that students should be able to, "Evaluate and treat a patient who has sustained a concussion or other brain injury, with consideration of established guidelines:" (Standard 76). In addition, students are required to, "Develop and implement specific policies and procedures for individuals who have sustained concussion or other brain injuries..." that includes protocols to be followed for immediate management, referral and progressive return to activities of daily living, school, sport, occupation and recreation (Standard 93) (CAATE, 2018). In Canada, the Committee of Academic Institutions (CAI) from the Canadian Athletic Therapists Association (CATA) has been working on developing the Athletic Therapy 
Competency Framework which outlines the different roles of an Athletic Therapist and the competencies required within each role to establish the standards for athletic therapy education (Lafave et al., 2019). Concussion knowledge, assessment and management are identified specifically in the roles of the Athletic Therapy Expert (Lafave et al., 202I) and the Collaborator (Lafave et al., 202I). While standards/competencies relating to concussion for athletic therapy and athletic training education have been established, the full extent of concussion assessment and management knowledge of athletic therapy professionals has yet to be explored.

In light of the variance relating to all aspects of concussion injury amongst health care practitioners, the purpose of this study was to gain an understanding of the perceived level of concussion assessment and management knowledge in a sample of athletic therapy students. Insight into athletic therapy students' concussion knowledge can help educators to design specific pedagogical activities/tools that help fill any existing knowledge gaps while engaging students in realistic concussion assessment and management simulations. Currently, delivery of the athletic therapy/athletic training standards and competencies for concussion injuries involves both theory and skill in the traditional classroom settings of lectures and guided laboratory sessions. Concussions are one of several injuries presented to students over the course of a semester and vary across institutions with respect to how many hours are dedicated to such a complex injury. In addition, students have the opportunity to apply their skills in field and clinical placements over the tenure of their program to help establish competency and learn experientially. As with any practical placement, however, the opportunity to respond to all injury types presented in the classroom is not always afforded due to the random nature of injury in general.

\section{METHODS}

\section{Methodological Tradition}

Complex phenomena, such as concussion assessment and management knowledge, cannot be explored exclusively through an objective, positivist research lens (Dean, 2018). This phenomenon is socially and contextually mediated by different personal, educational, technological, and institutional factors (Ashley \& Orenstein, 2005). For example, within the profession of athletic therapy/training each accredited institution has educators with their own teaching philosophies, varied pedagogical approaches/ strategies, students with diverse educational backgrounds, and unique clinical experiences, all of which cannot be controlled in a single research study. Based on these assumptions, we decided to follow an interpretivist approach to research by exploring the specific institutional factors that impacted concussion assessment and management knowledge in a single sample of students. Generalizability of these findings are then left to the reader as they can compare their own unique educational contexts to those described in this study (Stenfors-Haynes et al., 2013).

\section{RESEARCH DESIGN}

Following a sequential explanatory mixed-methods approach (Creswell \& Plano-Clark, 20I I), we explored the perceived level of concussion assessment and management knowledge in a sample of athletic therapy students. Following this approach helped us to gain a better understanding of the research problem, by taking advantage of the strengths of each type of quantitative and qualitative method (Ivankova et al., 2006). To investigate this research topic, we decided to gather initial data from a student questionnaire, followed by individual interviews with students and clinical educators. By gathering multiple data sets, we were able to corroborate the findings to ensure an enriched comprehensive account of the research phenomenon (Creswell \& Plano-Clark, 20II).

\section{Situating the Primary Investigator}

The primary investigator for this study was an academic researcher and certified athletic therapist, with experience in teaching concussion assessment and management. However, the primary investigator was not an employee of the accredited institution included in this study, and had no prior relationship with any of the students or clinical educators included in the sample.

\section{Participants}

Before the study commenced, institutional ethics review board approval was obtained from the accredited institution, as well as from the home institution of the primary investigator.

All athletic therapy students from an accredited institution of the CATA were invited to participate in the study.A total of fortythree students ( 23 women, 19 men, I did not wish to disclose) responded to the initial questionnaire. The sample had an overall grade point average of 6.72 on a 9-point scale. Seven students from the questionnaire sample ( 4 women, 3 men) participated in individual phone interviews. To further deconstruct emerging themes from the questionnaire and student interviews, three athletic therapy clinical educators ( 2 women; I man) participated in separate individual interviews.

\section{Situating Previous Concussion Education in the Sample of Athletic Therapy Students}

The majority of formalized concussion education for this sample of students was concentrated in two different half-year courses that encompassed multiple aspects of on-field athletic care. These courses were in the first of a 3-year program of study. In addition, students were engaged in on-field and clinical practicum placements (on-campus as well as with community partners) throughout the three years of the program, with variable exposure to different collision, contact and non-contact sports. Time spent working in the placements increased in both time (e.g. 2- 10 hours/ week) and level of supervision in relation to therapeutic responsibilities with each successive year.

\section{DATA COLLECTION PROCEDURES Student Questionnaire}

We designed an online questionnaire to explore general student knowledge of concussion assessment and management, as well as the specific role of an Athletic Therapist in assessing and managing concussions. Specific questions were modified from previous questionnaires developed by Register-Mihalik et al. (20I3) and Rosenbaum \& Arnett (2009). All modifications and edits supported the most recent assessment and management guidelines as set by the 2017 Concussion in Sport Group consensus statement (McCrory et al., 20 I7). Questions were organized into individual sections, including: I) indicating signs and symptoms of a concussion from a detailed list with distractors; 2) general concussion knowledge (e.g. common mechanisms of injury); 3) scenario-based field situations; and 4) 5-point Likert scale [ranging from I (strongly disagree) to 5 (strongly agree)] questions responding 
to statements about effective concussion assessment and management.After modifying the questionnaire, it was reviewed by three athletic therapy educators who were experienced with concussion education and questionnaire development. These educators were asked to assess for face validity by reviewing the research objectives and each specific question on the questionnaire. Minor grammatical edits were made after this process, to help improve the readability of the questionnaire.

All collected data from the student questionnaires were analyzed using Microsoft Excel 2016 (Redmond,WA), by way of means and standard deviations, to identify trends that were further deconstructed during the individual interviews.

\section{Individual Student Interviews}

Following the questionnaire, all participants were invited to participate in an individual phone interview with the primary investigator. These open-ended interviews followed a standardized, semi-structured format (Patton, 2002) to further discuss concussion knowledge in athletic therapy students, while also deconstructing trends that emerged from the questionnaire. Questions also aimed to explore various institutional and personal factors that contributed to concussion knowledge acquisition.All student interviews were audio-recorded (with permission from the participants) and manually transcribed by the primary investigator.

\section{Individual Clinical Educator Interviews}

In an attempt to triangulate the data, individual interviews were also completed with clinical educators who were affiliated with the accredited institution. These interviews were particularly useful in gaining access to student performance in practical settings, while identifying common gaps in concussion knowledge in athletic therapy students. These interviews also followed a standardized, semi-structured interview schedule to further discuss trends that emerged from the questionnaires and student interviews. Clinical educators were also asked to summarize their experiences with athletic therapy students to further discuss common areas for improvement with regards to concussion assessment and management. All clinical educator interviews were audio-recorded (with permission) and manually transcribed by the primary investigator.

\section{INTERVIEW DATA ANALYSIS AND TRUSTWORTHINESS}

An inductive content analysis approach (Hahn, 2008) was used to analyze all interview data with students and clinical educators. The first step of this process involved manually transcribing the interviews to gain a greater appreciation for what was said and how it was said. The next step involved reviewing all transcriptions to develop general coding categories to organize the interview data The final step of this thematic coding approach involved studying all general coded themes to further develop higher refined themes. Finally, the transcriptions were read again to find representative quotations that helped to support the overall research agenda and emergent themes.

We felt that data saturation was reached during the interviews with both students and clinical educators (Saunders et al., 2018). We believe that further data collection would yield similar results and confirm the emerging themes and conclusions from other samples within this accredited institution.
Through this process, trustworthiness was established through member checks and peer review (Patton, 2002).After all interviews were transcribed, coded, and analyzed, member checks were completed with two randomly selected interview participants to confirm the themes that emerged from the data. Transcripts were emailed to these randomly selected participants, and the thematic analysis was also shared. Follow-up interviews were scheduled to have further discussions about the emerging themes. Peer review was also used with the second author when reviewing the initial interview schedules and discussing the initial thematic analysis as proposed by the lead author. No major changes were made to any of the themes or subthemes after the member checking or peer review processes.

\section{RESULTS \\ General Concussion Knowledge}

In the questionnaire, participants were asked to identify potential concussion symptoms from a list of both real symptoms and distractors. Distractors were used to see if students were reading the symptom list, or simply responding with a blanketed response throughout the section (e.g. clicking yes for all responses). No participants in the sample identified all symptoms in the list, so it was assumed that they read through the list and selected what they thought the potential symptoms of a concussion to be. As seen in Table I, the entire sample of athletic therapy students correctly identified many common symptoms of a concussion, including: headache, "feeling pressure in the head", dizziness, balance problems, difficulty remembering, "feeling in a fog", and difficulty concentrating. However, several of the distractor symptoms were selected by multiple students in the sample, including:

\begin{tabular}{|c|c|}
\hline Symptom & Number of Responses (\%) \\
\hline Headache & $43(100)$ \\
\hline "Feeling pressure in the head" & $43(100)$ \\
\hline "Feeling in a fog" & $43(100)$ \\
\hline Abnormal sense of smell & $24(55)$ \\
\hline Abnormal sense of taste & $24(55)$ \\
\hline Amnesia & $37(86)$ \\
\hline Joint stiffness & II (25) \\
\hline Blurred vision & $42(97)$ \\
\hline Black eye & $16(37)$ \\
\hline Bleeding from ear & $27(62)$ \\
\hline Bleeding from mouth & $8(18)$ \\
\hline Bleeding from nose & $19(44)$ \\
\hline "Just not feeling right" & $42(97)$ \\
\hline Confusion & $42(97)$ \\
\hline Irritability & $43(100)$ \\
\hline \begin{tabular}{|l} 
Dizziness \\
\end{tabular} & $43(100)$ \\
\hline Neck pain & $41(95)$ \\
\hline Insomnia & $38(88)$ \\
\hline Loss of consciousness & $39(90)$ \\
\hline Nausea & $42(97)$ \\
\hline Numbness or tingling in arms & $25(58)$ \\
\hline Skin rash & $2(4)$ \\
\hline Sensitivity to noise & $41(95)$ \\
\hline Sharp burning pain in neck & $22(51)$ \\
\hline Weakness in neck movements & $29(67)$ \\
\hline Sensitivity to light & $41(95)$ \\
\hline More emotional & $40(93)$ \\
\hline Fever & $7(16)$ \\
\hline Vomiting & $43(100)$ \\
\hline Drowsiness & $41(95)$ \\
\hline "Feeling slowed down" & $42(97)$ \\
\hline Sadness & $40(93)$ \\
\hline Difficulty remembering & $43(100)$ \\
\hline Balance problems & $43(100)$ \\
\hline Difficulty concentrating & $43(100)$ \\
\hline Nervous or anxious & $37(86)$ \\
\hline
\end{tabular}


bleeding from the ear, bleeding from the mouth, bleeding from the nose, fever, and skin rash.

Following the symptom identification section, participants were then asked several general concussion knowledge questions. Table 2 shows the specific questions asked, as well as the frequency of correct responses submitted by students. The sample of students appeared to be knowledgeable about mechanisms of injury of a concussion, understanding that these injuries can occur without direct contact to the head.All students also recognized that there does not need to be loss of consciousness to be diagnosed with a concussion. However, there were two general knowledge questions that showed a greater variance in student response. Many students in the sample (35\%) did not believe that symptoms in most concussions resolve within 10-14 days, while $28 \%$ felt that brain imaging (e.g. CT scan or MRI) typically shows visible damage to the brain following a concussion.

\begin{tabular}{|l|c|}
\hline \multicolumn{1}{|c|}{ Table 2. Summaral Concussion Knowledge Question } & $\begin{array}{c}\text { Number of Correct } \\
\text { Responses (\%) }\end{array}$ \\
\hline $\begin{array}{l}\text { People who have had one concussion are more } \\
\text { likely to have another }\end{array}$ & 4 I (95) \\
\hline $\begin{array}{l}\text { There is rarely a risk to long term health and } \\
\text { well-being from multiple concussions }\end{array}$ & 43 (100) \\
\hline $\begin{array}{l}\text { To be diagnosed with a concussion, you have to be } \\
\text { knocked out }\end{array}$ & 43 (100) \\
\hline $\begin{array}{l}\text { An athlete who gets knocked out after getting a } \\
\text { concussion is experiencing a coma }\end{array}$ & 4 I (95) \\
\hline $\begin{array}{l}\text { A concussion can only occur if there is a direct hit } \\
\text { to the head }\end{array}$ & $43(100)$ \\
\hline $\begin{array}{l}\text { Being knocked unconscious always causes } \\
\text { permanent brain damage }\end{array}$ & $37(86)$ \\
\hline $\begin{array}{l}\text { Signs and symptoms of a concussion can last } \\
\text { several weeks }\end{array}$ & $43(100)$ \\
\hline $\begin{array}{l}\text { Sometimes a second concussion can help a person } \\
\text { remember things that were forgotten after the } \\
\text { first concussion }\end{array}$ & 4 I (95) \\
\hline $\begin{array}{l}\text { After a concussion, brain imaging typically shows } \\
\text { visible signs of physical damage to the brain }\end{array}$ & $31(72)$ \\
\hline $\begin{array}{l}\text { If you receive a concussion, and never had one } \\
\text { before, you will become less intelligent }\end{array}$ & $43(100)$ \\
\hline $\begin{array}{l}\text { After I0-I4 days, symptoms of a concussion are } \\
\text { usually completely gone }\end{array}$ & $28(65)$ \\
\hline $\begin{array}{l}\text { Concussions can sometimes lead to emotional } \\
\text { disruptions }\end{array}$ & $43(100)$ \\
\hline
\end{tabular}

\section{Concussion Assessment Knowledge}

To further evaluate for concussion assessment knowledge, students were asked to read multiple statements about concussion assessment and to then select a single number on a 5-point Likert Scale that best represented their answer. For these questions, I = strongly disagreed, 2 = disagreed, 3 = neither disagreed nor agreed, $4=$ agreed, and $5=$ strongly agreed with each respective statement. Table 3 shows the summary of responses, represented by the mean \pm standard deviation for each question.

Students in the sample felt that the Sport Concussion Assessment Tool (SCAT5) was expected of athletic therapy students to guide their concussion assessments in field settings. Participants also recognized the importance of not relying on solely subjective information by using multiple types of objective tests including assessing for spinal injury, cognitive evaluation, neurological evaluation, and balance tests. However, the student sample agreed with the statement "the best way to confirm a concussion is to compare the acute assessment results to baseline testing scores" which differs from the most recent Canadian Guideline on Concussion in Sport (Parachute 2020b). Although this topic
Table 3. Summary of Concussion Assessment Knowledge Questions

\begin{tabular}{|l|c|}
\hline \multicolumn{1}{|c|}{ Concussion Assessment Questions } & $\begin{array}{c}\text { Likert Responses } \\
\text { (Means } \pm \text { SD) }\end{array}$ \\
\hline $\begin{array}{l}\text { ATs are expected to use the SCAT5 to assess for } \\
\text { concussion }\end{array}$ & $4.79 \pm 0.56$ \\
\hline SCAT5 is the best concussion assessment tool available & $3.93 \pm 1.03$ \\
\hline $\begin{array}{l}\text { Every athlete suspected of having a concussion should } \\
\text { be immediately removed from a practice or game }\end{array}$ & $4.95 \pm 0.21$ \\
\hline $\begin{array}{l}\text { ATs are better trained to recognize concussion injuries } \\
\text { on the field of play than other healthcare professionals }\end{array}$ & $4.00 \pm 0.69$ \\
\hline $\begin{array}{l}\text { ATs should also assess for spinal injury when a concus- } \\
\text { sion is suspected }\end{array}$ & $4.71 \pm 0.50$ \\
\hline $\begin{array}{l}\text { It is critical to perform cognitive screening as part of a } \\
\text { concussion assessment }\end{array}$ & $4.71 \pm 0.55$ \\
\hline $\begin{array}{l}\text { Neurological screens are part of a standard concussion } \\
\text { assessment }\end{array}$ & $4.60 \pm 0.69$ \\
\hline $\begin{array}{l}\text { Balance tests must be conducted for every acute } \\
\text { concussion }\end{array}$ & $4.36 \pm 0.97$ \\
\hline $\begin{array}{l}\text { The best way to confirm a concussion is to compare } \\
\text { the acute assessment to baseline testing scores }\end{array}$ & $4.07 \pm 0.94$ \\
\hline ATs can diagnose a concussion for an athlete & $2.82 \pm 1.14$ \\
\hline
\end{tabular}

of baseline concussion testing has been frequently debated in the literature (Abeare et al., 20I8), evaluating the validity and reliability of baseline testing falls outside the scope of this study. However, it is important to note that the most recent recommendation to confirm a suspected concussion is to use an inter-disciplinary approach of multiple test batteries to assess each situation on an individual basis (Parachute, 2020a), not to rely on one specific or group of baseline tests.

Another noticeable finding that emerged from the data, was that there was almost a neutral response to the statement "Athletic Therapists can diagnose a concussion for an athlete". Although an Athletic Therapist is an important stakeholder in concussion recognition (due to the fact that these individuals are often the only group of health professionals to consistently be present during the initial concussion mechanism/presentation), it is outside of the scope of practice of an Athletic Therapist to diagnose any injury or medical condition. Therefore, any individual with a suspected concussion should be seen by a medical doctor for appropriate medical diagnosis as soon as possible following an injury (McCrory et al., 20l7).

\section{Concussion Management Knowledge}

To further assess for concussion management knowledge, students were asked to read multiple statements about concussion management and to then select a single number on a 5-point Likert Scale that best represented their answer. For these questions, $I$ = strongly disagreed, 2 = disagreed, 3 = neither disagreed or agreed, $4=$ agreed, and $5=$ strongly agreed with each respective statement. Table 4 shows the summary of responses, represented by the mean \pm standard deviation for each question.

Overall, the students from the sample appeared to understand important management recommendations, including: the importance of cognitive and physical rest during the initial 48-72 hours period, returning athletes to cognitive activities first before returning to physical activity, and following graduated exercise progressions during the return-to-play protocol. However, students were less confident in their response to the statement "Athletic Therapists are qualified to manage an athlete through all aspects of concussion". This was an important statement to further explore during the individual student interviews, to see which area(s) the sample felt that Athletic Therapists were not as qualified to help manage, and why. 


\begin{tabular}{|l|c|}
\hline \multicolumn{2}{|c|}{$\begin{array}{l}\text { Table 4. Summary of Concussion Management Knowledge } \\
\text { Questions }\end{array}$} \\
\hline \multicolumn{1}{|c|}{ Concusion Management Questions } \\
\hline $\begin{array}{l}\text { The best treatment for a concussion is to stay in a } \\
\text { quiet, dark room and avoid electronic devices for the } \\
\text { first } 48-72 \text { hours }\end{array}$ & $3.98 \pm 0.89$ \\
\hline $\begin{array}{l}\text { All concussion require some form of therapy in order } \\
\text { to resolve the injury }\end{array}$ & $3.48 \pm 1.05$ \\
\hline $\begin{array}{l}\text { The last symptom to resolve after a concussion is } \\
\text { typically a headache }\end{array}$ & $2.98 \pm 0.89$ \\
\hline $\begin{array}{l}\text { After sustaining a concussion, a physician must } \\
\text { clear an athlete before they can begin any form of } \\
\text { rehabilitation }\end{array}$ & $4.02 \pm 1.20$ \\
\hline $\begin{array}{l}\text { ATs are qualified to manage an athlete through a } \\
\text { graduated exercise progression for return to play }\end{array}$ & $4.62 \pm 0.49$ \\
\hline $\begin{array}{l}\text { Athletes must first be able to return to school/cogni- } \\
\text { tive activities before returning to physical activity }\end{array}$ & $4.12 \pm 0.91$ \\
\hline $\begin{array}{l}\text { The goal of placing athletes in non-contact training } \\
\text { drills is to increase the intensity of exercise and } \\
\text { thinking for the athlete }\end{array}$ & $4.29 \pm 0.82$ \\
\hline $\begin{array}{l}\text { There are strict guidelines for practitioners who op- } \\
\text { erate concussion clinics to ensure standardized care } \\
\text { for all athletes who have sustained a concussion }\end{array}$ & $3.90 \pm 0.75$ \\
\hline $\begin{array}{l}\text { ATs are qualified to manage an athlete through all } \\
\text { aspects of a concussion }\end{array}$ & $3.60 \pm 0.98$ \\
\hline
\end{tabular}

\section{Summary of Student Interviews}

The main goal of the student interviews was to further discuss the emerging themes from the questionnaire as described above. A summary of the emerging themes is presented in Figure I. Overall, the students that were interviewed felt that they had a good theoretical understanding about concussion recognition and assessment. Through their formal curriculum at the accredited institution, students felt that they were provided with the common signs and symptoms of a concussion, what to watch for in a field setting to indicate potential concussive injuries, and how to complete the SCAT5 assessment protocol with some supplemental tests (e.g. cranial nerve testing).Although there appeared to be a strong foundational base in the sample of athletic therapy students, several perceived gaps emerged from the interviews.

During the interviews, most of the students described a lack of knowledge of specific institutional policies during practicum placements. They also felt that the importance of knowing these specific protocols was not emphasized during their formal curriculum.

Some students described the concussion policies at their placement as being very clear, organized, and presented to the students as soon as they started their placement at the institution. However, others felt that the policies were either non-existent or not clearly articulated to the student until they were forced to find them independently. As an example, one student described their frustrations during a recent placement when,

I really didn't even think about the importance of knowing the specific concussion policies but then when I didn't follow the expected chain of command then the student had to miss time from school and I guess they didn't have the proper documentation so it came back to me as to why I didn't follow the policy. And my response was I didn't know about it! (Stu-2)

Another student added,

I only learned about the specific policies and protocols when a concussion actually happened. Which meant I wasn't as comfortable because I was left scrambling with figuring out

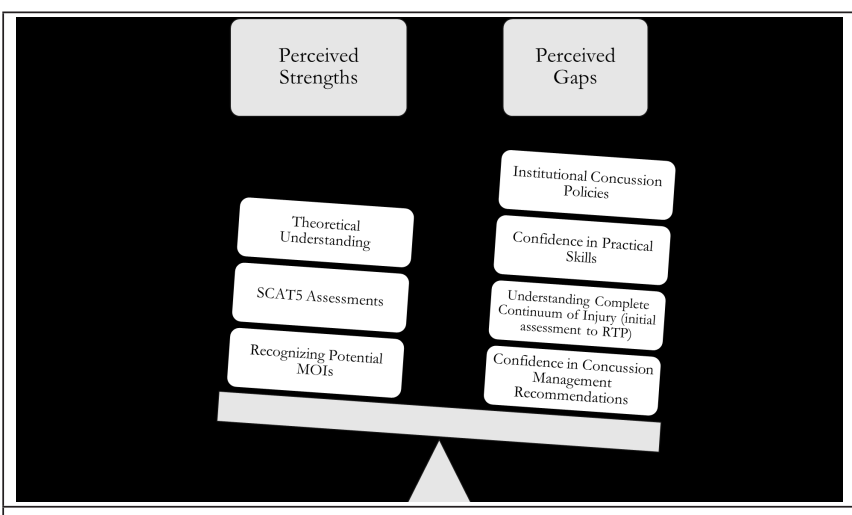

Figure I. Emerging Themes from Student Interviews

who to send them to, who to contact about missing class, etc. (Stu-7)

Six students of the interview sample also explained differences between their theoretical understanding of concussions and confidence in performing practical assessment/management skills. The students felt that a possible improvement for their program would be to practice with more realistic scenarios so that they could decide when to use certain tests/skills, especially since there is so much grey area in recognizing and assessing concussions. As one student indicated,

If you asked me what to do, I feel comfortable in answering that. But then actually doing it is a different thing. I feel like I haven't had the chance to practice the specific skills a whole lot so then when the time comes, I hope I will remember what to do and why. (Stu-5)

Another student added,

The trickiest thing is concussions are not textbook. Real life situations are completely different from what we learn about sometimes. So like I would like to be prepared for some of these things by practicing more real examples. (Stu-7)

The sample of students also recommended more examples that cover the entire continuum of concussion care, from the beginning of a situation (e.g. on-field assessment) all the way through a full return-to-play. Participants felt that they often learned about these important components in isolation of one another and were never really brought through complete examples of how everything flows from start to finish. As described earlier, formalized concussion assessment and management knowledge was delivered in different courses and did not provide students with the continuity of moving from initial recognition, to on-field assessment, to sideline assessment, to clinical assessment, etc. within the same individual. As one student stated,

As a student, I would like a detailed example that takes me from the beginning to the end of the situation. So that way I can think about how it all fits together. I find that we often learn about these things as if they are separate components but then when I go on placement I am expected to know it all. I would like it if we had a chance to work through a full example from start to finish. (Stu-I).

First and second-year students also discussed their lack of confidence in helping out during the concussion management process. The students that were interviewed felt that they were not well versed in making specific recommendations of what to do, other than just advising rest until the symptoms disappear. 
The students thought that they could learn more about important recommendations such as giving advice about sleeping, nutritional guidelines, subthreshold cognitive and physical activity, and when to perform or refer someone for more comprehensive treatment. Many of the students felt that they only learned about concussion management progressions when they were forced to take an athlete through it during practicum placements. As one student described,

There is a lot of self-learning with concussion management and rehab. We would learn during our placements about what to do. And sometimes these placements really helped because they had detailed protocols that we just had to follow. At other places, we had to do more self-learning about what to do and why. (Stu-2)

\section{Summary of Clinical Educator Interviews}

In an attempt to triangulate the data, individual interviews were also completed with clinical educators from the same accredited institution to further explore themes that emerged from the questionnaire and student interviews. These clinical educator interviews particularly focused on identifying common gaps in concussion knowledge in athletic therapy students, as well as exploring student competence in practical settings. A summary of the emerging themes is presented in Figure 2.

Similar to what was found during the student interviews, the most common gap in concussion knowledge identified by the clinical educators was the disparity between theoretical knowledge and practical ability. These educators felt that generally speaking, students experienced difficulties when actually applying their knowledge to real life situations. As one educator indicated,

Many students are not as comfortable with applying what they know during real time life action. Knowing when to pull an athlete, when to initiate an assessment, making decisions about when to sit someone out, etc. I also find that they sometimes do not trust their abilities. For example, they know what they should do during a situation but will not do it until told by their supervisor. (Educ-I)

Another clinical educator agreed by stating,

I feel that the students do not get enough hands-on concussion experience. So we go through all the theory with them but do not focus on as much the practical application side of things. So then the students are often not as confident in their abilities as they show on a theory based written exam. (Educ-2)

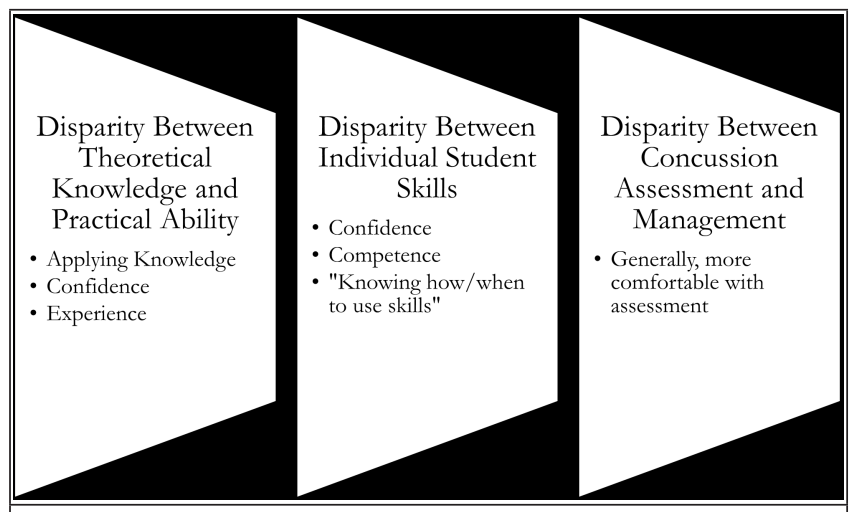

Figure 2. Emerging Themes from Clinical Educator Interviews
When exploring student competence development in practical settings, the sample of clinical educators felt that the students did not come to placement with a lot of hands-on skills on how to carry out a detailed assessment, or how to assist in the management process. Additionally, all educators also described differences between assessment and management knowledge, indicating that students are generally more comfortable with assessment, compared to management following a concussion. One clinical educator described this as

Most of the students appear to be missing a hands-on perspective. And it's hard to handle because some of the students are great and have a higher understanding of what they need to do, but then many others are not as confident in their practical abilities. So I think what can we do better to help increase their confidence and competence in actually performing assessment tests and rehabilitation plans. (Educ-I)

\section{DISCUSSION}

\section{Comparison of Concussion Assessment and Management Knowledge Across Health Professions}

The objective of this study was to gain an understanding of the perceived level of concussion assessment and management knowledge in a sample of athletic therapy students. Overall, the sample of students in this study scored highly on the theoretical knowledge component of the questionnaire. Students were able to recognize the most common signs and symptoms, understood mechanisms of injury of a concussion, understood the potential dangers of multiple concussions, and recognized important assessment and management statements. However, several knowledge gaps also emerged from the study, including: understanding the role of the Athletic Therapist in diagnosing/managing a concussion, understanding the importance of institutional concussion policies, and translating theoretical knowledge into practical competence. No known studies have explored concussion assessment and management knowledge in athletic therapy students, so our findings cannot be compared within this profession. Although comparable studies have found similar findings in other Canadian health professions.

Yorke et al. (2016) explored the attitudes, beliefs, knowledge, and practice of a sample of physical therapists in the treatment of patients with a concussion. This study identified several concussion knowledge gap areas including: understanding the clinical utilization of concussion severity scales, implementing conservative treatment with youth, the role of diagnostic imaging during assessment, and identifying the need for vestibular or manual therapy.

Kazemi and Bogumil (2017) investigated the degree of knowledge that sports chiropractors (certified and residents) had with concussion diagnosis and management. These researchers also identified several important knowledge gaps within their sample population, such as: identifying the less common signs and symptoms of a concussion, correctly identifying potential red flags indicating more significant conditions, and specific question items about concussion management.

Finally, a study by Boggild and Tator (2012) also explored concussion knowledge in a sample of medical students and neurology/neurosurgery residents. These researchers found that a significant number of medical students and residents had an 
incomplete knowledge about concussion diagnosis and management. The sample of $4^{\text {th }}$ year medical students only scored on average 4.2 correct answers out of 9 , compared to 5.8/9 for the residents. More specifically, the researchers identified gaps in recognizing the dangers of more significant conditions like second impact syndrome, the role of a physician in concussion assessment/management, and the seriousness of concussive injuries.

Since similar findings have been found throughout various health professional groups, all education programs could potentially benefit from self-evaluating how concussion assessment and management topics are taught within the formal curriculum of each program (Adomssent et al., 2007). This self assessment could lead to improved competence development in the areas of concussion assessment and management and ultimately help to better prepare health professionals to deal with this important injury.

\section{Theoretical Knowledge Versus Practical Ability} One of the central themes that emerged from this study was the discrepancies between theoretical concussion knowledge and practical abilities in athletic therapy students. Similar findings have been found in other health professions, including, physiotherapy (Barradell, 20l7), chiropractic education (Palmgren et al., 20l8), medical education (Hodges \& Kuper, 20I2), and nursing (Mackey \& Bassendowski, 2017). To be an effective health professional, both theoretical knowledge and practical knowledge are very important constructs to develop in students/residents but are often thought of as separate constructs (Frank et al., 20I0). Theory teaches a student to have a deeper understanding of what they are doing and why, whereas practical knowledge helps a student to understand how to do something in the real world (Frank et al., 20l0). According to seminal work by Remmen et al. (200I), written theory, or knowledge, must be the foundation on which practical skills are built upon. Every health care professional is required to understand the baseline theory or theoretical principles before they can effectively apply those skills to realistic practical situations. However, to promote the acquisition of theoretical knowledge and practical competence, educators should emphasize the importance of designing specific pedagogical activities that enable students to apply their theoretical knowledge in safe and realistic settings (Cutrer et al., 2017; Dornan et al., 201 I; Weller, 2004). This approach encourages students to understand what they are doing, with why they are doing it, while exploring other important contextual factors that occur during real-life experiences (Davis \& Harden, 2003). Based on these recommendations, educators should consider designing detailed pedagogical activities that engage students in realistic concussion and management situations, thus helping to bridge the gap between theoretical knowledge and practical skill development.

\section{RECOMMENDATIONS FOR HEALTH PROFESSIONAL EDUCATORS}

Since similar findings have been found across many different health professions, the themes that emerged from this study should be considered by all health professional educators to enhance concussion assessment and management instruction in each unique institution and/or professional context. Educators should work with clinical educators to ensure that specific institutional policies are made clear to students at the beginning of their placements. Each placement will have unique processes in place (e.g. who to contact when a concussion is suspected, what type of assessment to follow, how to document, what other professionals/ resources to inform) and it is pivotal that each student is made aware of this policy so they can follow the proper steps.

Educators should also reflect on how they teach students about concussions and explore alternative pedagogical strategies that could benefit students by enhancing their assessment and management competency. Within this study, it was suggested that students had difficulty in 'putting it all together' through the entire continuum of concussion care, from the initial assessment all the way to returning an athlete to full participation. Students felt that they often learned about concussions in pieces and did not experience complete examples from the initial injury to full clearance to return. Therefore, educators could explore a pedagogical strategy such as case-based learning to simulate realistic concussion experiences for their students. They could start an example from the initial assessment, progress to a more comprehensive clinical evaluation, then move on to initial management, provide direction for on-going management, and finally bringing the athlete through a complete return-to-learn/return-to-play protocol. This will allow a student to work through all these interconnected areas, while learning what is necessary to assist athletes during each stage.

Another recommendation for educators is to reflect on how they integrate theoretical knowledge with practical skill development as a part of their teaching. Habitually, medical educators often separate these constructs by teaching the theory to a student first, assume that the student will 'gain' this information on their own (often through rote memorization) and then attempt to build on practical skill development afterwards (Spicer et al, 2019). Constructivist theories of learning provide an alternative to this passive form of separating the theoretical from the practical. Constructivist learning is a much more active process that focuses on the context in which learning takes place and promotes students deriving meaning from their learning experiences (Richey et al., 20I I). The findings from this study demonstrated a sizable gap between student theoretical understanding and their abilities to carry out this knowledge during a real situation by using the traditional passive means of teaching. Therefore, educators should explore purposeful constructivist pedagogical activities that focus on creating realistic concussion simulations where the student can construct their own unique individual perspectives (Selwyn, 20I I). Educators can try to mimic reallife scenarios by getting the student to think about how they would recognize/respond to certain cues (e.g. when to send an athlete to the emergency department for a CT scan) while learning about what to do (practical skill development) and why (theoretical underpinnings). This approach could help to bridge the gap between theoretical knowledge and practical ability, and ultimately assist in developing true competence in assessing and managing concussions.

\section{LIMITATIONS AND FUTURE RESEARCH}

As with any form of research, our study had a few limitations. We decided to use a single accredited institution so that we could capture a better understanding of how the students were taught and how they performed in practical settings according to the perceptions of the clinical educators. Future research could expand to other athletic therapy accredited institutions, or other health professional groups, so that programs can iden- 
tify their own unique gaps.Another limitation was the number of students interviewed in our study. We had trouble recruiting for the individual interviews because they were scheduled during a busy time in the academic semester, when students were already balancing course work with demanding practicum placements. Future researchers should be cognizant of this and plan interviews towards the beginning or end of a semester when students have fewer practical commitments. Finally, the findings from this study encourage all athletic therapy accredited institutions to explore how they educate their own students about concussions, while identifying the specific types of activities/strategies dedicated to practical skill application and competence development. Future research should continue to investigate how these practical-based pedagogical activities impact knowledge acquisition and skill demonstration in any health professional education programs.

\section{CONCLUSIONS}

The main finding from this study was the large gap between theoretical knowledge and practical ability in athletic therapy students, leading to difficulties when assessing or managing concussive injuries in actual field settings. The sample of students in this study scored highly on the theoretical knowledge questionnaire but identified during the interviews that they were less confident when applying these concepts to real life situations. On the basis of the findings from this study, athletic therapy students could benefit from pedagogical strategies that help to bridge the gap between foundational concussion theory and practical application/competence development. Health professional educators can use this approach to explore how their own students are being prepared to deal with concussive injuries in actual real-life situations. By reflecting on the unique contextual strengths and weaknesses, the findings can be used to design pedagogical activities or tools to help engage students in realistic concussion assessment and management situations.

\section{REFERENCES}

Abeare, C.A., Messa, I., \& Zuccato, B. G. (20I8). Prevalence of invalid performance on baseline testing for sport-related concussion by age and validity indicator. JAMA Neurology, 75(6), 697-703.

Adomssent, M., Godemann, J., Michelsen, G., Barth, M., Rieckmann, M., \& Stoltenberg, U. (2007). Developing key competencies for sustainable development in higher education. International Journal of Sustainability in Higher Education, 8(4), 4I6-430.

Ashley, D., \& Orenstein, D. M. (2005). Sociological theory: Classical statements $\left(6^{\text {th }}\right.$ ed.). Boston, MA: Pearson Education.

Barradell, S. (2017). Moving forth: Imagining physiotherapy education differently. International Journal of Physical Therapy, 33(6), 439-447.

Boggild, M., \& Tator, C. H. (20I2). Concussion knowledge among medical students and neurology/neurosurgery residents. The Canadian Journal of Neurological Sciences, 39, 36I-368.

Broglio, S. P., Cantu, R. C., Gioia, G.A., Guskiewicz, K. M., Kutcher, J., Palm, M.,Valovich McLeod,T. C. (20I4). National Athletic Trainers' Association Position Statement: Management of Sport Concussion. Journal of Athletic Training, 49(2), 245-265.

Burke, M. J., Chundamala, J., \& Tator, C. H. (20I2). Deficiencies in Concussion Education in Canadian Medical Schools. The Canadian Journal of Neurological Sciences, 39, 763-766.
Carson, J. D., Rendely, A., Garel,A., Meaney, C., Stoller, J., Kaicker, J.,...Fremont, P. (20I6). Are Canadian clinicians providing consistent sport-related concussion management advice? Canadian Family Physician, 62, 494-500.

Commission on Accreditation of Athletic Training Education (2018). 2020 Standards for Accreditation of Professional Athletic Training Programs. https://caate.net/new-standards-releasefor-professional-masters-level-athletic-training-programs/

Creating Rowan's Law / Report of the Rowan's Law Advisory Committee (2017). Toronto, ON.

Creswell, J.W., \& Plano-Clark, V. L. (20I I). Designing and conducting mixed methods research (2nd ed.). Thousand Oaks, CA: SAGE Publications.

Cutrer,W. B., Miller, B., Pusic, M.V., Mejicano, G., Mangrulkar, R. S., Gruppen., ... \& Moore, D. E. (20I7). Fostering the development of master adaptive learners:A conceptual model to guide skill acquisition in medical education. Academic Medicine, 92(I), 70-75.

Davis, M. H., \& Harden, R. M. (2003). Competency-based assessment: making it a reality. Medical Teacher, 25(6), 565-568.

Dean, B.A. (2018). The interpretivist and the learner. International Journal of Doctoral Studies, 13, I-8.

Dornan, T., Mann, K.V., Scherpbier,A. J., \& Spencer, J.A. (20I I). Medical education:Theory and practice. London, UK: Elsevier Health Sciences.

Frank, J. R., Snell, L. S., Cate, O.T., Holmboe, E. S., Carraccio, C., Swing, S. R., ... \& Harden, R. M. (20I0). Competency-based medical education: theory to practice. Medical Teacher, 32(8), 638-645.

Hahn, C. (2008). Doing qualitative research using your computer:A practical guide. London, UK: SAGE Publications.

Hodges, B. D., \& Kuper,A. (20I2). Theory and practice in the design and conduct of graduate medical education. Academic Medicine, 87(I), 25-33.

Ivankova, N.V., Creswell, J.W., \& Stick, S. L. (2006). Using mixed-methods sequential explanatory design: From theory to practice. Field Methods, I8(I), 3-20.

Kazemi, M., \& Bogumil, M. E. (2017). Concussion knowledge among sport chiropractic fellows from the Royal College of Chiropractic Sports Sciences (Canada). The Journal of the Canadian Chiropractic Association, 6 I (3), 239-252.

Kazemi, M., Pichini, A., Scappaticci, S., Savic, M. (2016). Concussion assessment and management knowledge among chiropractic fourth year interns and residents. Journal of the Canadian Chiropractic Association, 60(4), 273-285.

Lafave, M. R., Owens, J. M., Eubank, B., \& DeMont, R. (202I). Development and validation of a new competency framework for athletic therapy in Canada. Athletic Training Education Journal, I6(I), 7I-86

Lebrun, C. M., Mrazik, M., Prasad, A. S., Tjarks, B. J., Dorman, J. C., Bergeron, M. F.,... Valentine,V. D. (20I3). Sport concussion knowledge base, clinical practices and needs for continuing medical education: a survy of family physicians and cross-border comparison. British Journal of Sports Medicine, 47(I), 54-59.

Mackey,A., \& Bassendowski, S. (2017). The history of evidence-based practice in nursing education and practice. Journal of Professional Nursing, 33(I), 5 I-55. 
McCrory, P. et al., (2017). Consensus statement on concussion in sport:The $5^{\text {th }}$ international conference on concussion in sport held in Berlin, October 2016. British Journal of Sports Medicine. I-I0.

Palmgren, P. J., Liljedahl, M., Lindquist, I., \& Laksov, K. B. (20 I8). A qualitative exploration of chiropractic and physiotherapy teachers' experiences and conceptualizations of the educational environment. Journal of Chiropractic Education, $32(1), 10-22$.

Parachute. (2020a). What to do if you suspect a concussion. Toronto, ON: Parachute. https://parachute.ca/en/injury-topic/ concussion/

Parachute. (2020b). Statement on concussion baseline testing in Canada. Toronto, ON: Parachute.

Patton, M. (2002). Qualitative research and evaluation (3rd ed.). Thousand Oaks, CA: SAGE Publications.

Register-Mihalik, J. K., Guskiewicz, K. M., \& Marshall, S.W. (20I3). Knowledge, attitude, and concussion-reporting behaviors among high school athletes: A preliminary study. Journal of Athletic Training, 48(5), 645-653.

Remmen, R., Scherpbier,A., Derese, A., Denekens, J., Hermann, I., Hoogenboom, R., ... Bossaert, L. (200I). Correlation of a written test of skills and a performance based test: Validation study in two traditional medical schools. Medical Teacher, 23(I), 29-32.

Richey, R. C., Klein, J. D., \& Tracey, M.W. (20I I). The instructional design knowledge base:Theory, research, and practice. New York, NY: Routledge.

Rosenbaum,A., \& Arnett, P.A. (2009). The development of a survey to examine knowledge about and attitudes toward concussion in high-school students. Journal of Clinical and Experimental Neuropsychology, 32(I), 44-55.

Saunders, B., Sim, J., Kingstone, T., Baker, S., Waterfield, J., Bartlam, B., et al. (2018). Saturation in qualitative research: Exploring its conceptualization and operationalization. Quality and Quantity, 52(4), I893-1907.
Selwyn, N. (20I I). Education and technology: Keys issues and debates. London, UK: Continuum International Publishing.

Spicer, D. B., Thompson, K. H., Tong, M. S., Cowan, T. M., Fulton, T. B., \& Lindsley, J. E. (20I9). Medical Biochemistry Without Rote Memorization: Multi-Institution Implementation and Student Perceptions of a Nationally Standardized Metabolic Map for Learning and Assessment. Medical Science Educator, 29(I), 87-92.

Stenfors-Hayes, T., Hult, H., \& Dahlgren, M.A. (20I3). A phenomenographic approach to research in medical education. Medical Education, 47(3), 26I-270.

Stoller, J., Carson, J. D., Garel, A., Libfeld, P., Snow, C. L., Law, M., Fremont, P. (20I4). Do family physicians, emergency departs physicians, and pediatricians give consistent sportrelated concussion management advice? Canadian Family Physician, 60, 548-552.

Weller, J. M. (2004). Simulation in undergraduate medical education: Bridging the gap between theory and practice. Medical Education, 38(I), 32-38.

Yorke, A. M., Littleton, S., \& Alsalaheen, B.A. (2016). Concussion attitudes and beliefs, knowledge, and clinical practice: Survey of physical therapists. Physical Therapy, 96(7), 1018 - 1028.

Zemek, R. L., Eady, K., Moreau, K., Farion, K. J., Solomon, B., Weiser, M., Dematteo, C. (20।4). Knowledge of pediatric concussion among front-line primary care providers. Pediatrics \& Child Health, 19(9), 475-480.

Zemek, R. L., Grool, A. M., Rodriguez Duque, D., DeMatteo, C., Rothman, L., Benchimol, E.,... Macpherson, A. K. (20I7).Annual and Seasonal Trends in Ambulatory Visits for Pediatric Concussion on Ontario between 2003 and 2013. Journal of Pediatrics, I8I, 222- 228. 